\title{
Strategies to Extend Bread and GF Bread Shelf-Life: From Sourdough to Antimicrobial Active Packaging and Nanotechnology
}

\author{
Valentina Melini * (i) and Francesca Melini \\ CREA Research Centre for Food and Nutrition, Via Ardeatina 546, I-00178 Roma, Italy; \\ francesca.melini@crea.gov.it \\ * Correspondence: valentina.melini@crea.gov.it; Tel.: +39-348-72-91-913
}

Received: 30 December 2017; Accepted: 29 January 2018; Published: 2 February 2018

\begin{abstract}
Bread is a staple food worldwide. It commonly undergoes physico-chemical and microbiological changes which impair its quality and shelf-life. Staling determines organoleptic impairment, whereas microbiological spoilage causes visible mould growth and invisible production of mycotoxins. To tackle this economic and safety issue, the bakery industry has been working to identify treatments which allow bread safety and extended shelf-life. Physical methods and chemical preservatives have long been used. However, new frontiers have been recently explored. Sourdough turned out an ancient but novel technology to preserve standard and gluten-free bread. Promising results have also been obtained by application of alternative bio-preservation techniques, including antifungal peptides and plant extracts. Active packaging, with absorbing and/or releasing compounds effective against bread staling and/or with antimicrobials preventing growth of undesirable microorganisms, showed up an emerging area of food technology which can confer many preservation benefits. Nanotechnologies are also opening up a whole universe of new possibilities for the food industry and the consumers. This work thus aims to provide an overview of opportunities and challenges that traditional and innovative anti-staling and anti-spoilage methods can offer to extend bread shelf-life and to provide a basis for driving further research on nanotechnology applications into the bakery industry.
\end{abstract}

Keywords: bread and gluten-free bread; shelf-life; sourdough; antimicrobial active packaging; food nanotechnologies

\section{Introduction}

Bread is a staple food worldwide and it comes in many types, shapes, sizes and texture, depending on national and regional traditions. It can be consumed as artisan bread, freshly prepared every day by bakers, or it can be found as commercially packaged sliced bread. According to the International Association of Plant Bakers (AIBI), there is a great number of differences in the patterns of bread production and consumption among European countries. In Greece, Turkey and Italy, craft bakeries represent the highest share and are a rooted food tradition, while in Bulgaria, the Netherlands and the UK, there are high percentages of market share of industrial bakeries, which meet the growing demand for sliced and wrapped bread [1].

Bread is a dynamic system undergoing physical, chemical and microbiological changes which limit its shelf-life. Physical and chemical changes determine loss of freshness, in terms of desirable texture and taste, and lead to the progressive firming-up of the crumb. Microbiological spoilage by bacteria, yeasts and moulds consists on visible mould growth, invisible production of mycotoxins and formation of off-flavours, which might be produced even before fungal outgrowth is visible. Spoiled bread hence represents a matter of concern, as it causes enormous food waste (i.e., $5-10 \%$ world bread production 
losses) [2] and economic losses both for the bakery industry and the consumer [3], as well as human intoxication due to contamination with fungal mycotoxins. The latter are, in fact, often associated with several acute and chronic diseases in humans [4].

To tackle this economic and safety issue, the bakery industry has long been working to identify and implement strategies and methods which allow a longer bread shelf-life, the lowest number of changes in bread organoleptic quality, and also bread safety.

Physical methods like ultra violet (UV) light, Infrared (IR), microwave (MW) heating, ultra-high pressure (UHP) treatments are used to destroy post-baking contaminants [5]. Chemical preservatives, such as acetic acid, potassium acetate, sodium acetate, and others are applied in accordance to the limits laid down by the Regulation (EC) No. 1333/2008 on food additives [6]. Sourdough has also recently become an established form of food bio-preservation and the role played by lactic acid bacteria (LAB) as bio-agents and inhibitors to bread spoilage has been scientifically explored and highlighted.

Active packaging is one more option, with the rationale of absorbing and/or releasing compounds effective against bread staling and/or antimicrobials preventing the growth of undesirable microorganisms [7]. Nanotechnologies have been also applied in order to design active packaging and are opening up a whole universe of new possibilities for both the food industry and the consumers.

The aim of this work is to provide an overview of the opportunities and challenges that traditional and innovative anti-staling and anti-spoilage methods can offer to extend bread shelf-life and to provide a basis for driving further research on nanotechnology applications into the bakery industry. In details, an overview of factors causing bread staling and spoilage is first provided, and traditional and current strategies used to extend bread shelf-life are discussed. Future trends of packaging systems in food preservation are then presented with emphasis on antimicrobial active packaging and nanotechnology applications. A hint at promising results obtained from the application of traditional and innovative methods to extend gluten-free (GF) bread shelf-life is also given.

\section{Methods}

\subsection{Literature Search}

The study layout was first designed and an extensive literature search for papers on major literature databases such as SCOPUS, PubMed, ScienceDirect was conducted September to December 2017. Several combinations of terms related to bread shelf-life and food packaging were used: bread shelf-life, bakery products shelf-life, gluten-free bread shelf-life, bread staling, bread spoilage, sourdough, bread packaging, active packaging, bread and nanotechnology, bread and nanoparticles, bread and silver nanoparticles, bread and montmorillonite, bread and essential oils, bread and antimicrobials. During the search, time limits were also set-the year of publication was to be later than 2007 , in order to collect the most up-to-date published works.

The websites of authoritative Institutions, namely the European Food Safety Authority, Food Agriculture Organization and World Health Organization were also consulted.

\subsection{Including and Excluding Criteria}

Duplicate papers, articles not accessible for authors, or research studies dealing with foods other than bread and bakery products were excluded.

Reference lists of articles were also scanned to further identify relevant papers that were not found in electronic databases. A screening of the full text resulted in a further exclusion of papers. 


\section{Results}

\subsection{Factors Affecting Bread Shelf-Life}

\subsubsection{Bread Staling}

Bread staling refers to all the chemical and physical changes that occur in the crust and crumb during storage and that gradually decrease consumer acceptance, as it is no longer considered "fresh". It is accompanied by loss of crispiness, increase in crumb firmness and crumbliness (loss of cohesion), and loss or change of taste and aroma [8]. Staling is, in fact, mainly detected organoleptically by the changes in bread texture, taste and aroma.

The overall staling process thus consists in two separate phenomena: the firming effect caused by moisture transfer from crumb to crust during storage, and the intrinsic firming of the cell wall material which is associated with starch re-crystallization during storage [9]. In the first case, the crust readily absorbs moisture from the interior crumb, which has a moisture content of about $45 \%$. Evidence shows that during a storage period of $100 \mathrm{~h}$, the crust moisture may increase to 28\% [9]. Crumb staling is, on the other hand, a more complex, as well as less understood phenomenon, and the failure to understand the mechanism of the process is the key hindrance to the development of a preventive strategy for bread staling.

Many theories have been nevertheless proposed and discussed so far, such as the important role of starch retrogradation, specifically of amylopectin retrogradation, despite it is not directly responsible for bread staling, the role of gluten proteins and of the gluten-starch interactions.

Storage temperature, moisture migration, crumb-crust redistribution of moisture, and moisture redistribution among components are other factors affecting staling rate. Some anti-staling inhibitors are amylases and debranching enzymes, lipases, lipoxygenases, non-starch polysaccharide-modifying enzymes, proteases, surface-active lipids, and others.

As far as gluten-free (GF) bread is concerned, staling represents one of the major issues, as it is mainly based on starch [10]. Moreover, gluten-free bread often contains a greater density of fat than its gluten-containing counterparts [11], hence it likely undergoes lipid oxidation. Off-flavours formation might thus impair GF bread sensory profile.

\subsubsection{Bread Spoilage}

Bread ingredients are supportive to growth of microorganisms and multiplication thereof at various stages of bread production, processing, packaging and storage. Moulds, yeasts and bacteria are the main causative agents of bread microbial spoilage. They are able to grow under a great variety of conditions, also where other microorganisms are not competitive, and are able to survive in the bakery environment [12].

Mould growth is the most common cause of bread spoilage. Moulds are actually responsible for post-processing contamination. Bread taken fresh out of the oven is, in fact, free of moulds and spores thereof, since they are inactivated by heat during the baking process; however, loaves can be contaminated by moulds during cooling, slicing, packaging and storage, as the environment inside a bakery is not sterile and is a likely source of contamination [9]. Mould development on bread is slow and if the relative humidity of the atmosphere is below $90 \%$ they do not grow; however, moulds can grow rapidly in a humid atmosphere and especially on loaf inside a wrapper. When bread is wrapped hot from the oven, water droplets condense on the inside surface of the wrapper and mould growth is promoted. Sliced wrapped bread is even more susceptible to mould spoilage as a wider surface is exposed to mould infections. Several factors can influence the rate of mould growth: the type of flour, the processing method, the packaging and the storage conditions.

Rhizopus nigricans, with its white cottony mycelium and black dots of sporangia, the green spored Penicillium expansum or P. stolonifer, and Aspergillus niger with its greenish to black conodial heads are the most commonly moulds involved in bread spoilage and they are thus referred to as "bread 
mould" [9] (Table 1). In detail, in wheat bread Penicillium, Aspergillus, Cladosporium, Mucorales and Neurospora species have been observed, with Penicillium spp. being the most common type of bread mould. In black bread, Rhizopus (nigricans) stolonifer is the most common spoilage mould and it appears as a white cottony mycelium and black sporangia.

Table 1. Major causative agents of bread microbial spoilage.

\begin{tabular}{|c|c|c|}
\hline & ge Agents & Properties of Colony \\
\hline \multirow{9}{*}{ Moulds } & Penicillium spp. & Blue/green, flat, spread rather slowly \\
\hline & Aspergillus niger & $\begin{array}{l}\text { Black, fluffy, spreading with sporeheads } \\
\text { often clearly visible }\end{array}$ \\
\hline & Aspergillus flavus & Olive green \\
\hline & Aspergillus candidus & Cream \\
\hline & Aspergillus glaucus & Pale green \\
\hline & Cladosporium spp. & Dark olive green, flat, spread slowly \\
\hline & Neurospora stophila & Salmon pink, fluffy and fast spreading \\
\hline & Rhizopus nigricans & Grey/black, very fluffy and fast spreading \\
\hline & Mucor spp. & Grey \\
\hline Bacteria & $\begin{array}{l}\text { Bacillus subtilis or Bacillus } \\
\text { licheniformis }\end{array}$ & Irregular shape, white and dull colour \\
\hline \multirow{8}{*}{ Yeasts } & Hyphopichia burtonii & \multirow{3}{*}{$\begin{array}{c}\text { Slow growth on bread surface, low, white, } \\
\text { spreading colonies }\end{array}$} \\
\hline & Pichia anomala & \\
\hline & Scopsisfi buligera & \\
\hline & Pichia burtonii & Very fast growth on bread \\
\hline & Zygosaccharomyces bailii & \multirow{4}{*}{$\begin{array}{l}\text { Smooth, round, convex and white to cream } \\
\text { coloured }\end{array}$} \\
\hline & Torulaspora delbrueckii & \\
\hline & Pichia membranifaciens & \\
\hline & Candida parapsilosis & \\
\hline
\end{tabular}

Some moulds are also responsible for mycotoxin production, thus they present a severe risk to public health.

Although the dominant bread spoilage microbiota is comprised of moulds, sporeforming bacteria represent one more serious matter of concern for bread quality and safety. Sporeforming bacteria are likely present on the outer parts of grains, and subsequently in the air of the bakery environment, and hence ingredients and/or bakery equipment are the primary source of contamination [13].

The main causative microorganism of bacterial spoilage is Bacillus subtilis, whose spores form endospores and easily survive baking, and can then germinate and grow within 36-48 h inside the loaf to form the characteristic soft, stringy, brown mass with an odour of ripe pineapple or melon due to the release of volatile compounds, such as diacetil, acetoin, acetaldehyde and isovaler-aldehyde [9]. Bacteria also produce amylases and proteases that degrade the bread crumb.

Other species, such as Bacillus pumilus, Bacillus amyloliquefaciens, Bacillus megaterium, Bacillus licheniformis, and Bacillus cereus, have been also identified [13] (Table 1). According to a recent study by Valerio and colleagues (2012) [14], B. amyloliquefaciens might actually be the main species related to the occurrence of rope spoilage, as in previous works it was mis-identified as B. subtilis.

Yeast spoilage is the least common of all types of microbial spoilage, and yeasts, like moulds, do not survive the baking process. Contamination rather occurs during cooling, and, in case of industrial bread, it especially happens during the slicing step. 
More than 40 species of fungi have been described as contaminant agents of baked foods [15]. They are responsible of yeast spoilage, which especially determines bread off-odours. In particular, when spoilage is due to fermentative yeasts, an alcoholic or estery off-odour is usually recorded. Saccharomices cerevisiae, which is generally used as baker's yeast, tends to be encountered most often.

Contamination can be also due to filamentous yeasts. In that case, the phenomenon known as "chalky bread" occurs. It means that white spots develop in the crumb. This type of spoilage is sometimes confused with mould growth; however, the distinction can be made because yeasts produce single cells and reproduce by budding. H. burtonii, P. anomala and Scopsis fibuligera are responsible for early spoilage of bread products, growing in low, white, spreading colonies that sometimes look like sprinkling of chalk dust on the product surface [16]. The most common and troublesome chalk mould is, however, P. burtonii which grows very fast on bread, and is very resistant to preservatives and disinfectants. Otherwise, yeast spoilage can be caused by Z. bailii, T. delbrueckii, Pichia membranifaciens, and Candida parapsilosis [17] (Table 1). The same moulds, bacteria and yeasts are causative agents of GF bread microbial spoilage.

\subsubsection{Gluten-Free Bread Shelf-Life}

GF bread shelf-life deserves a separate analysis and discussion, because of the different formulation of this bread in comparison with standard bread, which implies additional challenges in identifying and optimizing preservative strategies.

GF bread is mandatory formulated with GF flours, and the lack of gluten implies at technological level some differences from standard breadmaking [10]. When GF ingredients are mixed, the suspension of air resulting from the mixing process and the carbon dioxide obtained from yeast fermentation cannot be entrapped in the gluten network which does form in standard breadmaking [10]. The result is hence the formation of irregular and unstable cells, leading to lack of cell structure, a reduced volume and a dry, crumbly and grainy texture. GF dough also has a more fluid-like structure and generally contains higher water levels than wheat-based dough, if acceptable crumb wants to be obtained [18]. Upon formation of a complex emulsion-foam system and of a large number of minute air bubbles, surface-active ingredients (e.g., egg whites, lipoproteins) are also generally added, as they allow the entrapment of bubbles by the formation of a protective film around the gas bubbles, and also prevent them from coalescing. Gums, stabilizers, and pre-gelatinized starches are also used, so that gas occlusion and stabilization can occur [10,19]. However, the very high level of water, the addition of fat ingredients and/or GF starches determine in GF bread a more rapid firming behaviour and a higher susceptibility to microbial spoilage $[18,20,21]$. Some researchers also proposed that in wheat bread the gluten network slows down water migration from crumb to crust and moisture loss, hence in GF bread a faster ageing can be observed [20,22].

Staling represents one of the major issues in GF bread, as this latter is often mainly based on starchy ingredients [10]. Interestingly, the ingredients themselves determine a more rapid or slow staling process. For example, it was observed that rice-based GF bread is more prone to retrograde during storage than wheat bread [23]. This might be explained by the fact that a predominant factor regarding bread staling is likely related to starch retrogradation as well, which involves a progressive association of gelatinized starch segments into a more ordered structure, but also the water activity $\left(\mathrm{a}_{\mathrm{w}}\right)$. Rice bread has a very high $\mathrm{a}_{\mathrm{w}}(\approx 0.987)$ which determines a lower microbial stability and hence shelf-life.

However, more recently, the Irish research group led by E. Arendt has observed that other factors other than the presence of absence of gluten may influence the staling rate of GF bread, among which the ratio of amylase to amylopectin [24]. 


\subsection{Traditional Methods to Improve Bread Shelf-Life}

\subsubsection{Physical Treatments}

The bakery industry has traditionally relied on the use of physical methods to extend bread shelf-life, and UV light, IR radiation, MW heating or UHP are some examples.

In detail, UV light is a powerful anti-bacterial treatment, with the most effective wavelength being $260 \mathrm{~nm}$. It is used to control the occurrence of mould spores on bread, and among applications there is direct UV irradiation of the surfaces of wrapped bakery products which allows an extension of shelf-life. It is nevertheless worth mentioning a generally poor penetrative capacity, and the difficulty to treat a multi-surfaced product, as mould spores likely present in the air cell walls within the bread surface are protected from the irradiation [8].

MW heating allows heating rapidly and evenly loaves of bread without major temperature gradients between the surface and the interior. Generally, a 30-60 s treatment allows making wrapped bread mould-free. However, the application of this treatment is limited by the fact it can cause condensation problems which can hence adversely affect the appearance of the product [8].

IR treatment can also be used to destroy mould spores, with the advantage of not adversely affecting the quality and appearance of the product or the integrity of the packaging material [8]. Moreover, IR treatment minimizes problems due to condensation or air expansion. Among disadvantages, it is worth mentioning it is quite costly for multi-sided products which are required either to rotate between heaters or to be treated in two separate ovens [8].

\subsubsection{Chemical Treatments}

Chemical preservatives can be used alternatively. Weak organic acids (e.g., propionic and sorbic acid) are used to stifle the growth of undesired microorganisms and hence extend bread shelf-life. However, application limits have been laid down within the European Union, and are currently regulated by Regulation (EC) No. 1333/2008 of the European Parliament and of the Council of 16 December 2008 on food additives [6].

Generally speaking, potassium, sodium or calcium salts of propionic and sorbic acid are the forms most generally used because of the higher water solubility and easier handling than their respective corrosive acids [25]. The limits of $0.2 \%(w / w)$ and $0.3 \%(w / w)$ are established for sorbate and propionate addition, respectively (EEC, 2008), in both prepacked sliced bread and rye bread. In case of prepacked unsliced bread, a maximum of $0.1 \%$ propionate is only permitted.

It was observed that addition of high concentrations of sorbate or propionate are desired for antifungal activity, but it likely implies the alteration of bread sensory properties. Moreover, prolonged usage of these preservatives against spoilage fungi may lead to the development of fungal resistance to them $[26,27]$.

In vitro screening experiments have shown that the addition of propionate to rye sourdough bread is not recommended due to the resistance of P. roqueforti [28], as well as to the fact that propionate has only slight effect in mould inhibition when included in bread at $\mathrm{pH} 6$ [2].

As regards sorbate, it seems to be more efficient than propionate at inhibiting bread spoilage, but it is rarely used in breadmaking because of its negative impact on bread volume [29].

Addition of ethanol is one more traditional method and it is somehow preferable to other chemical preservatives. Ethanol concentrations ranging between $0.2 \%$ and $12 \%$ are reported to increase bread shelf-life [30]. Moreover, its addition on bread surface $(0.5 \% w / w)$ contributes to improving sorbate and propionate effect [31]. Berni and Scaramuzza (2013) [32] have recently observed ethanol potential to inhibit Crysonilia sitophila, more commonly known as "the red bread mould", and H. burtoni, also known as "the chalky mould", on packed and sliced bread at very low $(0.8 \%)$ and medium $(2.0 \%)$ ethanol concentrations, respectively. Interestingly, it is also worth mentioning that no restrictions apply to the use of ethanol as a food preservative, although its presence on labels must be listed. Being it an effective additional barrier to inhibit fungal growth in bread and/or bakery products in general, 
promising results have been stressed by Hempel and colleagues (2013) [33] upon addition of ethanol emitter in active packaging.

\subsubsection{Sourdough}

In the past, natural and flavoured bread with a long shelf-life was obtained instinctively, using a traditional long fermentation process: sourdough. Based on that, the bakery industry has recently started to reconsider this traditional fermentation method to possibly replace chemical preservatives and thus guarantee a clean label. Sourdough has thus become an established form of food bio-preservation and the role played by LAB as bio-agents and inhibitors to bread spoilage has been scientifically explored and highlighted.

Robust scientific foundation has been found for the ability of sourdough to retard staling, protect bread from spoilage, and subsequently contribute to extending bread shelf-life [15,34,35]. Lactobacillus acidophilus ATCC 20079, Lactobacillus amylovorous DSM 19280, Lactobacillus brevis R2 $\Delta$, Lactobacillus fermentum Te007, Lactobacillus hammesii, Lactobacillus paracasi D5, Lactobacillus paralimentarius PB127, Lactobacillus pentosus G004, Lactobacillus plantarum, Lactobacillus reuteri R29, Lactobacillus rhamnosus, Lactobacillus rossiae LD108, Lactococcus BSN, Pediococcus acidilactici KTU05-7, Pediococcus pentosaceus KTU 05-8 and KTU 05-10, as well as Leuconostoc citreum $\mathrm{C} 5$ and $\mathrm{HO} 12$ are some of the LAB strains with an interesting bio-preservative action on bread when used as starter cultures [36].

The use of LAB-fermented sourdough in itself, nevertheless, allows achieving just a low preservative effect. Acidification through sourdough fermentation was found to inhibit the endospore germination and growth of Bacillus spp. responsible for rope spoilage [37]. However, the $\mathrm{pH}$ drop and the acidification, which is usually associated with the production of lactic and acetic acids, are reportedly parameters which can extend bread shelf-life only to a limited extent and/or do not extensively influence mould inhibition [2].

The anti-bacterial, anti-microbial and anti-fungal ability, that sourdough LAB have shown to possess, is related to the active compounds that they produce and/or release and which are complementary to chemical preservatives or can even substitute their use. The metabolites which mainly exert anti-fungal activity are specifically low molecular mass compounds, such as cyclic dipeptides, hydroxyl-fatty acids, phenyl and substituted phenyl derivatives (e.g., 3-phenyllactic, 4-hydroxypenyllactic, and benzoic acid), diacetyl, hydrogen peroxide, caproate, reuterin, and fungicidal peptides.

Heterofermentative LAB specifically release anti-fungal organic acids [38]. Lactobacillus sanfranciscensis CB1 produces, for instance, a mixture of organic acids, such as acetic, butyric, caproic, formic, $n$-valeric, and propionic ones. The anti-mould activity of this microorganism against Fusarium, Penicillium, Aspergillus and Monilia spp. is mainly due to these compounds [39]. Strains of $L b$. plantarum have shown to exert a broad anti-fungal activity, thanks to the production of inhibiting compounds like 4-hydroxyphenlyllactic and phenyllactic acid. It is also evident that sourdough started with anti-fungal strains of $L b$. plantarum allows to reduce the content of calcium propionate in wheat bread by $\approx 30 \%$, with no negative effect on bread shelf-life [40]. $L b$. reuteri releases active concentrations of reutericyclin, a low molecular weight antibiotic active against Gram-positive LAB and yeasts, as well as reuterin, a compound containing the hydrated monomeric and cyclic dimeric forms of 3-hydroxypropionaldehyde, and having antimicrobial activity toward several food spoilage organisms, among which Gram-positive and -negative bacteria, yeasts and moulds.

These compounds are nevertheless present with a relatively high minimal inhibition concentration, which ranges from 0.1 to $10,000 \mathrm{mg} / \mathrm{kg}$ [2], despite being produced in low amount in the fermentation substrate. For that reason, it has been hypothesized that the antifungal inhibitory mechanism likely originates from complex mechanisms of synergy among the low molecular mass compounds [2]. 
As regards the synergistic activity of compounds and the antifungal effect of sourdough LAB, $L b$. reuteri, $L b$. plantarum and $L b$. brevis showed to delay fungal growth by eight days in the presence of calcium propionate $(0.2 \%, w / w)$, The antifungal activity which Lactobacillus buchneri and Lactobacillus diolivorans have against growth of moulds on bread has been often attributed to a combination of acetate and propionate. The preservative effect of $L b$. amylovorous has been attributed to the synergy among more than ten antifungal compounds, including cyclic dipeptides, fatty acids, phenyllactate and phenolic acids. Interestingly, it has been also observed that production of antifungal compounds in sourdough is species- and substrate-specific [2].

The synergy of LAB metabolic versatility, favoring adaptation to the various processing conditions; the mechanisms of proto-cooperation with autochthonous yeasts during sourdough fermentation; the carbohydrate and amino acid metabolism; the synthesis of organic acids, exopolysaccharides and antimicrobial compounds, as well as the conversion of phenolic compounds and lipids by LAB are rather the key parameters to investigate, in order to understand the role played by LAB as a key biotechnology in bread preservation [38,41,42]. The antifungal effect of sourdough LAB is attributed to the synergistic activity of several compounds.

The role played by yeasts other than baker's yeast (i.e., S. cerevisiae) is also worth mentioning. Their application has been, in fact, suggested as a promising alternative for bread preservation. Wickerhamomyces anomalus LCF1695 is, for instance, used as a mixed starter in combination with Lb. plantarum 1A7 [43]; Meyerozyma guilliermondii LCF1353 harbour marked antifungal activity toward P. roqueforti DPPMAF1; sourdough fermented with a combined starter culture-M. guilliermondii LCF1353, W. anomalus LCF1695 and Lb. plantarum 1A7 strain-allows to obtain excellent results in terms of extended shelf-life [44].

In addition to the antifungal metabolites of lactic acid bacteria, the preservative effect of inhibitory peptides derived from the substrate has been also observed. A water-extract from beans in combination with sourdough fermented with $L b$. brevis AM7 contained three natural inhibitory compounds, two phaseolins and one lectin. The combined activity thereof determined a delay in fungal growth of up to 21 days, leading to a shelf life for the bread that was comparable to that found when using Ca propionate $(0.3 \% w / w)$.

\subsection{Novel Strategies to Improve Bread Shelf-Life: Active Packaging}

Following the development of the Active and Intelligent Packaging Regulations by the European Commission [45], active packaging can be defined as packaging intended to extend the shelf-life of packaged foods or to maintain and/or improve the condition thereof by releasing or absorbing substances into or from the food or its surroundings. Alongside intelligent packaging, active packaging belongs to innovative packaging systems that are supposed to interact with the food and are not only a mere passive barrier protecting and preserving packaged food from physical, chemical and biological damage, as conventional packaging is.

Different types of active packaging systems are available. Generally speaking, they can be mainly categorized as absorbing and releasing systems [46]. The former remove undesired compounds, such as oxygen, from the package environment, while the latter release compounds, such as antioxidants, preservatives and antimicrobials, to the packaged food or into the head-space of the package [46]. Absorbers and releasers can come in the form of a sachet, a label or a film. Commonly sachets are placed in free form in the package head-space, while labels are fixed into the lid. Any direct contact with food should be prevented, as the function of the system might be impaired and migration might occur. Nanotechnology also enabled designing polymers with improved barrier function against oxygen.

As far as bread and GF bread are concerned, active packaging absorbing oxygen and releasing antimicrobials has been used in order to extend the shelf-life thereof. 


\subsubsection{Active Packaging with Oxygen Absorbers}

Inclusion of an oxygen absorber in the packaging has been used in bakery products, such as bread and cakes, and in prepared foods, e.g., sandwiches and pizza [47].

Oxygen increases the rate of bread and bakery products staling, and promotes the lipid oxidation in bread containing fats, such as rye bread and GF bread. As a consequence, removing oxygen from the packaging will contribute to preserve the bread desirable texture and taste.

Strategies, such as the removal of oxygen from package by vacuum technology, are not suitable for bakery products. As a matter of fact, vacuum packaging evacuates most of the oxygen present in the package to levels less than $1 \%$, and oxygen is removed also from bread interior pores. This would cause the collapse of bread and rolls, and bread organoleptic properties commonly appreciated by consumers, such as softness, would be lost.

The use of Modified Active Packaging (MAP) to extend bread shelf-life has some drawbacks, as well. In detail, the highly porous structure does not permit complete oxygen elimination and the interchange with gas flowing through the package. Hence, oxygen may persist in the food package. The quantity of oxygen detected in the package headspace may also depend on packaging material permeability to this gas. In case of packaging permeability, oxygen can accumulate over time to a level sufficient to support mould growth [48].

The addition of oxygen absorbers in the packaging to ensure oxygen removal has been proposed as an alternative strategy to overcome vacuum and MAP packaging drawbacks.

Oxygen absorbers, such as ATCO ${ }^{\circledR}$ (Standa Industrie, Caen, France) or Ageless ${ }^{\circledR}$ (Mitsubishi Gas Chemical Co., Tokyo, Japan) have been used to reduce the concentration of oxygen in food packaging. The effectiveness of $\mathrm{ATCO}^{\circledR}$ oxygen absorbers in extending the microbial shelf-life of sliced bread has been investigated and it was observed that the oxygen concentration decreased to below $0.1 \%$ within a few days of packaging. In addition, the absorbers did not have any effect on the sensory quality of bread over the storage [49]. Hence, oxygen absorbers enabled to prevent both bread staling and spoilage, since oxygen is an essential factor of growth of mould and strictly aerobic microorganisms. In 1998, Berenzon and Saguyf [50] studied the effect of oxygen absorbers in reducing lipid oxidation of military ration crackers at various storage temperatures (i.e., 15,25 and $35^{\circ} \mathrm{C}$ ) over 52 weeks. Nielsen and Rios (2000) [51] investigated the effect of oxygen absorbers on decreasing spoilage organisms such as Penicillium commune and P. roqueforti. They also observed that $A$. flavus and Endomyces fibuliger persisted at oxygen levels of $0.03 \%$. However, the combination of oxygen absorbers with essential oils from mustard (Brassica spp.), cinnamon (Cinnamomum spp.), garlic (Allium sativum) and clove (Syzygium aromaticum) were found effective [51]. More recently, Latou and colleagues (2010) [52] found that the use of an oxygen absorber in combination with an alcohol emitter was as effective as chemical preservatives are (e.g., calcium propionate and potassium sorbate) in decreasing the growth of yeasts, moulds and B. cereus. The system also inhibited lipid peroxidation and rancid odours for 30 day treatment.

In general, oxygen scavenging technologies are based on iron powder oxidation, ascorbic acid oxidation, catechol oxidation, photosensitive dye oxidation, enzymatic oxidation, unsaturated fatty or immobilised yeast on a solid material [46]. Nevertheless, the majority of oxygen absorber systems is based on the ability of iron to form non-toxic iron oxide under appropriate humidity conditions [46]. As a consequence of iron oxidation, rust formation can be observed. The system is contained in a sachet to prevent the iron powder from imparting colour to the food. Nevertheless, the use of sachets have some drawbacks. They could leak out and contaminate the product. Hence, the absorbers might be accidentally ingested by the consumer. Polymer films and labels have been developed to overcome these issues [46].

Oxygen absorbers must meet specific criteria to be effective and succeed commercially. In detail, they should absorb oxygen at an appropriate rate, should be compact and uniform in size, should not be toxic, nor produce unfavorable side reactions. The choice of oxygen absorbers is influenced by food 
properties, such as size, shape, weight and $\mathrm{a}_{\mathrm{W}}$ of the food, the amount of dissolved oxygen in the food, the desired shelf-life of the product and the permeability of the packaging material to oxygen [53].

\subsubsection{Active Packaging with Releasers: Antimicrobial Releasing Systems}

Antimicrobial active packaging is the most common active packaging system which releases antimicrobial agents into the food surface (where microbial growth predominates) inhibiting or retarding microbial growth and spoilage. The main goals of an antimicrobial active packaging system are (i) safety assurance, (ii) quality maintenance, and (iii) shelf-life extension; as a consequence, antimicrobial packaging could play an important role in food safety assurance.

Several antimicrobial agents may be incorporated in the packaging system, namely chemical antimicrobials, antioxidants, biotechnology products, antimicrobial polymers, natural antimicrobials and gas. The most commonly used are organic acids, fungicides, alcohols and antibiotics [46].

Organic acids, such as benzoic acids, parabens, sorbates, sorbic acid, propionic acid, acetic acid, lactic acid, medium-size fatty acids and mixture thereof, have strong antimicrobial activity and have been used as preservatives in food preparations.

Fungicidal activity was reported for benomyl and imazalil. Antioxidants were also reported effective antifungal agents, due to the restrictive oxygen requirement of moulds [46].

Among alcohols, ethanol has shown a strong antibacterial and antifungal activity, despite it is not effective against the growth of yeast. However, the use of ethanol in food packaging has some drawbacks due to strong undesirable chemical odour. As far as bread and bakery products are concerned, active packaging ethanol emitter systems have been used to extend the shelf-life thereof. The use of ethanol in food packaging is under 2011/10/EC Regulation [54]. It has been generally regarded as safe (GRAS) in the United States as a direct human food ingredient. Labuza and Breene (1989) [55] report the use of Ethicap ${ }^{\circledR}$, a food grade alcohol adsorbed onto silicon dioxide powder and contained in a sachet made up of a copolymer of paper and ethyl vinyl acetate. The polymer releases ethanol vapor at a concentration ranging $0.5-2.5 \%(v / v)$ that acts as an antimicrobial agent when condensing on the food surface. Vanilla and other compounds are used to mask the alcohol flavour. Ethicap ${ }^{\circledR}$ has several advantages: (i) ethanol vapor can be generated without spraying ethanol solutions directly onto products prior to packaging; (ii) sachets can be conveniently removed from packages and discarded at the end of the storage period; (iii) low cost. Franke and colleagues (2002) [56] also reported the use of Ethicap ${ }^{\circledR}$ in pre-baked buns $\left(a_{w}=0.95\right)$ packaging. They found that packaging into gamma sterile PE-LD bags with Ethicap ${ }^{\circledR}$ delayed mould growth for 13 days, at room temperature. Previously, Smith and colleagues (1990) also observed that ethanol vapor generators were effective in controlling 10 species of moulds, including Aspergillus and Penicillium species, 15 species of bacteria, including Salmonella, Staphylococcus and Escherichia coli, and the species of spoilage yeast [57]. More recently, ethanol emitters have been used in combination with essential oils. Koukoutsis and colleagues (2004) [58] evaluated the water-ethanol (WE) and mastic oil-ethanol (ME) emitters to control the growth of microorganisms in high-moisture and high $\mathrm{pH}$ bakery products. Besides preventing or delaying bread spoilage, ethanol is effective against bread staling since it acts as a plasticizer of the protein network of the bread crumb [53].

Antibiotics might be also used as antimicrobials, but they are not approved for the purpose of antimicrobial functions, and their use is also controversial due to the development of resistant microorganisms.

Unfortunately, no antimicrobial agent effectively works against all spoilage and pathogenic microorganisms. As a consequence, the microorganism properties, such as oxygen requirement (aerobes and anaerobes), composition of the cell wall (Gram positive and Gram negative), the growth-stage they are at (spores and vegetative cells), the optimal temperature for growth (thermophilic, mesophilic and psychrotropic) and resistance to acid/osmosis are fundamental to select the more appropriate antimicrobial agent. 


\subsubsection{Nanotechnology Application in Active Packaging}

Currently, the food industry is pioneering the application of nanotechnology in active food packaging, in order to extend food shelf-life and improving food safety (Figure 1).

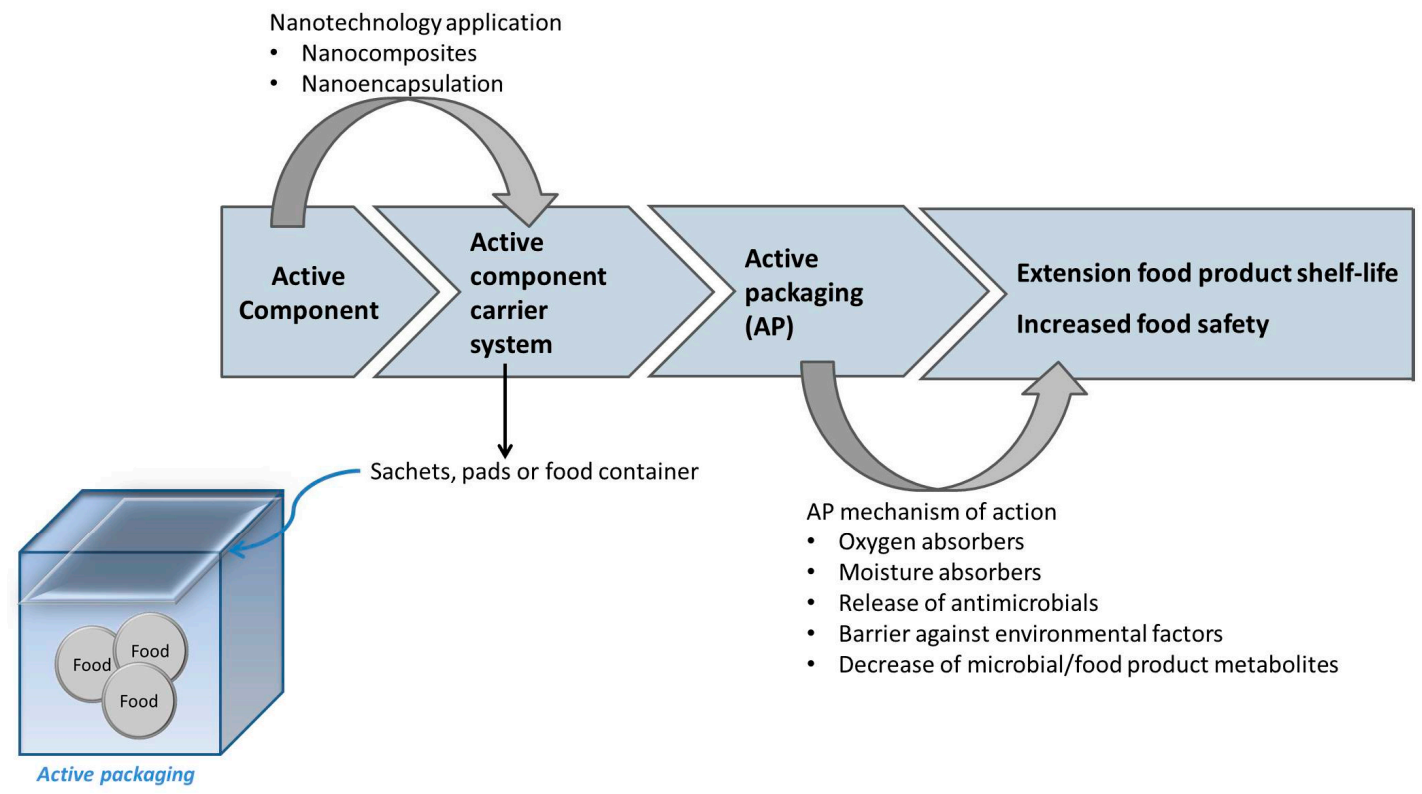

Figure 1. Application of nanotechnology and mechanism of action of active packaging in extending bread and GF bread shelf-life, and increasing food safety.

Nanotechnology has been applied in the production of nanocomposites and in the encapsulation of active compounds.

Nanocomposites are multiphase materials characterized by a polymer (continuous phase) merged to nano-dimensional material (discontinuous phase) that can come in form of inorganic or organic fibers, flakes, spheres or particulates, commonly referred to as "fillers" [54,55]. Hence, nanocomposites are a fusion of traditional packaging polymers with nanoparticles.

Generally speaking, the inclusion of fillers in nanoscale improves mechanical strength of food package materials and reduces the weight thereof. Nanocomposites have also improved barrier ability against oxygen, carbon dioxide, ultraviolet radiation, moisture and volatiles. In addition, they may (i) let air and other enzymes out but not in, (ii) degrade ripening gas, such as ethylene, and (iii) have antimicrobial activity [56,58-63]. Hence, nanocomposites may be used to extend food shelf-life, thus reducing the addition of man-made preservatives in foods.

Several materials, namely metal, metal oxides, metal hydroxides, silica, clay, polysaccharide nanocrystals, carbon nanotubes, chitosan and cellulose have been explored as fillers [64].

Silver nanoparticles, metal oxide (such as titanium dioxide $\left(\mathrm{TiO}_{2}\right)$, zinc oxide $(\mathrm{ZnO})$ and magnesium oxide $(\mathrm{MgO})$ ) and metal hydroxide (such as calcium hydroxide $\left(\mathrm{Ca}(\mathrm{OH})_{2}\right)$ and Magnesium hydroxide $\left.\left(\mathrm{Mg}(\mathrm{OH})_{2}\right)\right)$ nanoparticles have been used in antimicrobial food packaging applications [65].

The mechanism of action of silver nanoparticles in microorganisms and moulds has been investigated, and it has been shown that they can penetrate into the outer and inner membranes of the cells, disrupting barrier components, such as lipopolysaccharides and proteins. The antimicrobial activity thereof has been attributed to both their ability to inhibit respiratory chain enzymes and disrupt the normal DNA replication and cellular proteins activation processes, as well [62-69]. Moreover, silver nanoparticle antimicrobial activity is due to the ability to produce reactive oxygen species that cause oxidative stress to microbial cells [70].

Silver nanoparticles have been also integrated or combined in systems used for bacteria inactivation and have been used in antifouling applications. Orsuwan and colleagues (2016) [71] 
integrated silver nanoparticles in agar and banana powder films, and composites systems were obtained. They exhibited antimicrobial activity against food-borne pathogenic bacteria, such as E. coli and Listeria monocytogenes. Kanmani and colleagues (2014) [72] incorporated silver nanoparticles in gelatin and they found that bacterial pathogens, such as S. typhimurium, L. monocytogenes, E. coli, S. aureus, and B. cereus, were significantly inhibited in a dose-dependent manner. In detail, Gram-negative $S$. typhimurium was found to be more susceptible to silver nanoparticles, followed by Gram-positive B. cereus and S. aureus. Pathogens, such as L. monocytogenes and E. coli, were less susceptible to the silver nanoparticles in the gelatin films.

Silver nanoparticles were also integrated in Graphene Oxide and the resulting surfaces were found to inhibit almost up to $100 \%$ of bacteria attachment [73].

Silver nanoparticles anchored on common surfaces, such as glass, also inhibit the formation of biofilms [74], then they were used as antifouling systems.

Clay and silicates have been also used as nanoparticles in the production of intercalated and exfoliated nanocomposites [75]. The former have a multilayered structure with alternating polymer/filler layers lying apart by few nanometers, while in the latter the filler layers are delaminated and randomly dispersed in the polymer matrix [76]. Anyway, the presence of the filler in polymer increases the tortuosity of the diffusive path for a penetrant molecule, hence it provides the material with excellent barrier properties [59]. Montmorillonite, a hydrated alumina-silicate layered clay consisting of an edge-shared octahedral sheet of aluminum hydroxide between two silica tetrahedral layers is the most widely studied type of clay fillers [59]. Agarwal and colleagues (2014) [77] compared the shelf-life of bread stored in polypropylene films (control packaging) and in polypropylene films coated with montmorillonite-nylon 6 (MMT-N6) nanofibres. They determined the fungal and microbial growth at the end of 5th storage day and observed fungal growth on bread packed in control packets, while no growth was found in test packets. As far as the microbial count is concerned, bread samples packed in polypropylene packets at the end of 5 days showed $2.9 \times 104 \mathrm{CFU} / \mathrm{g}$, while in nanocoated packets the microbial count was $92 \mathrm{CFU} / \mathrm{g}$. At the end of 7 th day of storage, control bread showed microbial growth in the range of $7.25 \times 104 \mathrm{CFU} / \mathrm{g}$ of bread sample, and bread packed in MMT-N6 coated packets showed $230 \mathrm{CFU} / \mathrm{g}$ of bread sample. Hence, the use of MMT-N6 coated films enables to increase bread shelf life of almost 2 days, which is quite significant for both industry and consumer. Montmorillonite has been used also combined to silver nanoparticles to extend the shelf-life of foods other than bread.

Silver nanoparticles have been widely used in food packaging, even combined to metal oxides. Cozmuta and colleagues (2014) [78] investigated the effect of silver/titanium dioxide $\left(\mathrm{Ag} / \mathrm{TiO}_{2}\right)$-based packaging on bread shelf-life and they found that proliferation of yeast/moulds, B. cereus and B. subtilis was reduced compared to bread stored in open atmosphere or in common plastic package. Moreover, they found that the degradation rate of the main nutritional compounds also decreased. More recently, Peter and colleagues (2016) [79] investigated the possibility of using paper packages modified with $\mathrm{Ag} / \mathrm{TiO}_{2}-\mathrm{SiO}_{2}, \mathrm{Ag} / \mathrm{N}-\mathrm{TiO}_{2}$ and $\mathrm{Au} / \mathrm{TiO}_{2}$ to extend white bread shelf-life. They found packages with $\mathrm{Ag} / \mathrm{TiO}_{2}-\mathrm{SiO}_{2}, \mathrm{Ag} / \mathrm{N}-\mathrm{TiO}_{2}$ paper enabling to extend bread shelf-life by 2 days, while no effect was observed by using $\mathrm{Au} / \mathrm{TiO}_{2}$ paper.

Silver nanoparticles have been also included in polypropylene food containers such as Fresher Longer $^{\mathrm{TM}}$ Plastic Storage and BagsFresherLonger ${ }^{\mathrm{TM}}$ Miracle Food Storage. They were reported to keep bread and also fruits, vegetables, herbs, cheeses, soups, sauces, and meats fresher 3 or even 4 times longer and to reduce the bacterial growth by $98 \%$ compared to conventional food containers [80].

Nanoencapsulation of antimicrobial agents is also an example of application of nanotechnology to extend bakery products shelf-life Generally speaking, encapsulation protects the antimicrobial compounds against chemical reactions and undesirable interactions with food components and controls the delivery thereof [81]. Compared to microencapsulation that guarantees protection of antimicrobial compounds against degradation or evaporation, the high surface area to volume ratio 
of the nanoencapsulation systems enables to concentrate the antimicrobials in food areas where microorganisms are preferably located [82].

Nanoencapsulation has been also used in order to obtain antimicrobial packaging systems. This technology has been applied to essential oils that can act as potent antimicrobials, may present antifungal activity and/or have antioxidant properties. A major drawback in using essential oils is that they must be added in small amounts to foods to prevent the deterioration of food sensory properties. The nanoencapsulation of essential oils enables to overcome this issue. It consists in coating essential oils within another material at sizes in the nanoscale in order to increase the protection thereof, reduce evaporation, promote easier handling, and control their release during storage and application. The combination of essential oils with paper, edible films based on milk proteins, chitosan, or alginates has been experimented with. Otoni and colleagues (2014) [83] reported the incorporation of microand nanoemulsions of clove bud (Syzygium aromaticum) and oregano (Origanum vulgare) essential oils into films from methylcellulose in order to extend slice bread shelf-life. They studied mould and yeast growth over 15 days and found that at 15 days of storage, bread placed in the antimicrobial film from methylcellulose and nanoemulsions of clove bud and oregano essential oils showed the lowest count of yeasts and moulds, followed by a bread sample added with a commercial antifungal (sorbic acid, calcium propionate, ethanol, and alcohol) and then by a bread sample placed in oil-free methylcellulose film/metalized polypropylene bags (which were sealed and stored at $25 \pm 2{ }^{\circ} \mathrm{C}$ in an effort to simulate usual commercialization conditions of bakery products bread).

In 2011, Gutierrez and colleagues [84] investigated the effect of an active packaging with cinnamon essential oil label combined with MAP to increase the shelf-life of gluten-free sliced bread. They found that the active packaging considerably increased the shelf-life of packaged food maintaining the sensory properties of the gluten-free bread.

Souza and colleagues (2013) [85] investigated the effect of different amounts of cinnamon essential oil on antimicrobial activity, mechanical and barrier properties of films from of cassava starch, glycerol and clay nanoparticles and they found that all films showed effective antimicrobial activity against $P$. commune and E. amstelodami, fungi that are commonly found in bread products.

\subsubsection{Safety Concerns of Active Packaging and Nanotechnology Application in Food} Products/Legislation

The EC Regulation No. 1935/2004 sets out the general principles of safety and inertness for all Food Contact Materials, namely food packaging [86]. The principles set out in the above-mentioned regulation require that materials do not release their constituents into food at levels harmful to human health and do not change food composition, taste and odour in an unacceptable way.

Actually, active packaging is not inert, by its design, and may release or absorb substances to or from the food or its surrounding environment. Hence, active packaging is exempted from the general inertness rule in Regulation (EC) No. 1935/2004 and is regulated by EC regulation No. 450/2009 [45]. The released substance has to be authorized by food legislation and should undergo a safety assessment by EFSA before being authorized. Moreover, it can be released only in authorized quantities. Regulation (EC) No. 450/2009 also foresees the establishment of a list of substances permitted for the manufacture of active materials.

As far as the application of nanotechnology to food packaging, little is known about the fate and toxicity of nanoparticles and there is an urgent need for specific guidelines for testing of nanofoods.

In 2011, the European Food Safety Authority (EFSA) published a scientific opinion (EFSA Scientific Committee, 2011) to be intended as a practical approach to assessing potential risks of nanomaterials application to food and feed chain. In the above-mentioned document, EFSA stated that data about interaction between nanomaterials and food matrices, behaviours of nanomaterials in human body and methods to determine such interactions and behaviours are missing, despite their relevance for risk assessment. 
Also FAO and WHO jointly developed a technical paper on the State of the art on the initiatives and activities relevant to risk assessment and risk management of nanotechnologies in the food and agriculture sectors. In the document, national and international scientific (i.e., risk assessment related) and regulatory (i.e., risk management) activities on applications of nanotechnology in food and agriculture were reviewed in order to set up the context for future needs and perspective.

Actually, the difficulty to characterize, detect and measure nanoparticles alone and in complex matrices, such as food and biological samples [87] leads to the lack of exhaustive and complete toxicological data.

\section{Conclusions and Future Perspectives}

Active packaging is an emerging area of food technology that can confer many preservation benefits on a wide range of food products. The main goal of active packaging systems is to maintain sensory quality and extend the shelf life of foods while maintaining nutritional quality and ensuring microbial safety. This results in decrease of food waste at the same time.

Nanocomposite films have/display anti-microbial properties thanks to anti-microbial agents and because of their improved structural integrity, which results from the barrier properties created by the addition of nanofillers. In addition to the use as packaging materials, nanocomposites can be also used as delivery systems by helping the migration of functional additives, namely antimicrobials. Nanoclays can be used as carriers for the active agents, as well. Further developments of active packaging and the application of nanotechnology to packaging will depend on safety issue and consumer acceptance.

So far, the application of nanotechnology to food extend bread and bakery products shelf-life has been poorly exploited, however, it might enable to retain bread organoleptic properties, especially of GF bread and reduce bread spoilage, thus reducing bread waste.

The main advantages of active packaging for bakery product distributors are increased stock rotation cycle times and extension of the geographic distribution network. Consumer can also take advantage from active packaging, since bakery product can be stored unrefrigerated for longer time and ready anytime as fresh tasting meal or snack.

Sourdough fermented with anti-fungal and anti-mould strains of LAB is also an area of increasing focus, besides allowing the production of GF bread with enhanced nutritional value, quality and safety. Moreover, it is so far in-line with consumer's quest for "natural" products, that is, products containing fewer additives. Promising results have been also obtained by the application of other alternative bio-preservation techniques, including the utilization of antifungal peptides and plant extracts. The latter can be also added to bread formulations or incorporated in antimicrobial films for active packaging of bread.

Author Contributions: The study was conceived by both authors. Francesca Melini collected the information on bread spoilage and on traditional methods to improve bread shelf-life and wrote the relative paragraphs. Valentina Melini collected the information on bread staling and active packaging to improve bread shelf-life. Francesca Melini and Valentina Melini jointly worked at the introduction and conclusions. Both authors read and accepted the final manuscript.

Conflicts of Interest: The authors declare no conflict of interest.

\section{References}

1. Association of Plant Bakers. AIBI Aisbl AIBI Bread Report-AIBI. Available online: http://www.aibi.eu/ aibi-bread-report/ (accessed on 27 December 2017).

2. Axel, C.; Zannini, E.; Arendt, E.K. Mold spoilage of bread and its biopreservation: A review of current strategies for bread shelf life extension. Crit. Rev. Food Sci. Nutr. 2017, 57, 3528-3542. [CrossRef] [PubMed]

3. Melikoglu, M.; Webb, C. Food Industry Wastes: Chapter 4. Use of Waste Bread to Produce Fermentation Products; Elsevier Inc.: San Diego, CA, USA, 2013; ISBN 978-0-12-805884-8. 
4. Oliveira, P.M.; Zannini, E.; Arendt, E.K. Cereal fungal infection, mycotoxins, and lactic acid bacteria mediated bioprotection: From crop farming to cereal products. Food Microbiol. 2014, 37, 78-95. [CrossRef] [PubMed]

5. Smith, J.P.; Daifas, D.P.; El-Khoury, W.; Koukoutsis, J.; El-Khoury, A. Shelf life and safety concerns of bakery products-A review. Crit. Rev. Food Sci. Nutr. 2004, 44, 19-55. [CrossRef] [PubMed]

6. Regulation (EC) No 1333/2008 of the European Parliament and of the Council of 16 December 2008 on Food Additives. Available online: http://eur-lex.europa.eu/legal-content/EN/ALL/?uri=CELEX\% 3A32008R1333 (accessed on 27 December 2017).

7. Van Long, N.N.; Joly, C.; Dantigny, P. Active packaging with antifungal activities. Int. J. Food Microbiol. 2016, 220, 73-90. [CrossRef] [PubMed]

8. Cauvain, S.P.; Young, L.S. Technology of Breadmaking; Springer Science \& Business Media: New York, NY, USA, 2007; ISBN 978-0-387-38565-5.

9. Pateras, I.M.C. Bread spoilage and staling. In Technology of Breadmaking; Springer: New York, NY, USA, 1998; pp. 240-261, ISBN 978-1-4613-5922-7.

10. Melini, F.; Melini, V.; Luziatelli, F.; Ruzzi, M. Current and Forward-Looking Approaches to Technological and Nutritional Improvements of Gluten-Free Bread with Legume Flours: A Critical Review. Compr. Rev. Food Sci. Food Saf. 2017, 16, 1101-1122. [CrossRef]

11. Miranda, J.; Lasa, A.; Bustamante, M.A.; Churruca, I.; Simon, E. Nutritional differences between a gluten-free diet and a diet containing equivalent products with gluten. Plant Foods Hum. Nutr. 2014, 69, 182-187. [CrossRef] [PubMed]

12. Cauvain, S. Bread Spoilage and Staling. In Technology of Breadmaking; Springer International Publishing: New York, NY, USA, 2015; pp. 279-302, ISBN 978-3-319-14686-7.

13. Lavermicocca, P.; Valerio, F.; De Bellis, P.; Sisto, A.; Leguérinel, I. Chapter 16-Sporeforming bacteria associated with bread production: Spoilage and toxigenic potential. In Food Hygiene and Toxicology in Ready-to-Eat Foods; Kotzekidou, P., Ed.; Academic Press: San Diego, CA, USA, 2016; pp. 275-293, ISBN 978-0-12-801916-0.

14. Valerio, F.; De Bellis, P.; Di Biase, M.; Lonigro, S.L.; Giussani, B.; Visconti, A.; Lavermicocca, P.; Sisto, A. Diversity of spore-forming bacteria and identification of Bacillus amyloliquefaciens as a species frequently associated with the ropy spoilage of bread. Int. J. Food Microbiol. 2012, 156, 278-285. [CrossRef] [PubMed]

15. Gänzle, M.; Gobbetti, M. Physiology and Biochemistry of Lactic Acid Bacteria. In Handbook on Sourdough Biotechnology; Gobbetti, M., Gänzle, M., Eds.; Springer: Boston, MA, USA, 2013; pp. 183-216, ISBN 978-1-4614-5424-3.

16. Legan, J.D.; Voysey, P.A. Yeast spoilage of bakery products and ingredients. J. Appl. Bacteriol. 1991, 70, 361-371. [CrossRef] [PubMed]

17. Deak, T. Handbook of Food Spoilage Yeasts, Second Edition. Available online: https://www.crcpress. com/Handbook-of-Food-Spoilage-Yeasts-Second-Edition/Deak/p/book/9781420044935 (accessed on 6 May 2017).

18. Recent Advances in the Formulation of Gluten-Free Cereal-Based Products-ScienceDirect. Available online: http:/ / www.sciencedirect.com/science/article/pii/S0924224403002590 (accessed on 27 December 2017).

19. Zannini, E.; Jones, J.M.; Renzetti, S.; Arendt, E.K. Functional replacements for gluten. Annu. Rev. Food Sci. Technol. 2012, 3, 227-245. [CrossRef] [PubMed]

20. Gallagher, E.; Kunkel, A.; Gormley, T.R.; Arendt, E.K. The effect of dairy and rice powder addition on loaf and crumb characteristics, and on shelf life (intermediate and long-term) of gluten-free breads stored in a modified atmosphere. Eur. Food Res. Technol. 2003, 218, 44-48. [CrossRef]

21. Moroni, A.V.; Bello, F.D.; Zannini, E.; Arendt, E.K. Impact of sourdough on buckwheat flour, batter and bread: Biochemical, rheological and textural insights. J. Cereal Sci. 2011, 54, 195-202. [CrossRef]

22. Sciarini, L.S.; Ribotta, P.D.; León, A.E.; Pérez, G.T. Effect of hydrocolloids on gluten-free batter properties and bread quality. Int. J. Food Sci. Technol. 2010, 45, 2306-2312. [CrossRef]

23. Kadan, R.S.; Robinson, M.G.; Thibodeaux, D.P.; Pepperman, A.B., Jr. Texture and other Physicochemical Properties of Whole Rice Bread. J. Food Sci. 2001, 66, 940-944. [CrossRef]

24. Hager, A.-S. Cereal Products for Specific Dietary Requirements. Evaluation and Improvement of Technological and Nutritional Properties of Gluten Free Raw Materials and End Products. Ph.D. Thesis, University College Cork, Cork, Ireland, 2013. 
25. Magan, N.; Arroyo, M.; Aldred, D. Mould Prevention in Bread. In Bread Making: Improving Quality; Woodhead Publishing: Boca Raton, FL, USA, 2003; pp. 500-514, ISBN 978-1-85573-553-8.

26. Levinskaite, L. Susceptibility of food-contaminating Penicillium genus fungi to some preservatives and disinfectants. Ann. Agric. Environ. Med. 2012, 19, 85-89. [PubMed]

27. Stratford, M.; Nebe-von-Caron, G.; Steels, H.; Novodvorska, M.; Ueckert, J.; Archer, D.B. Weak-acid preservatives: $\mathrm{pH}$ and proton movements in the yeast Saccharomyces cerevisiae. Int. J. Food Microbiol. 2013, 161, 164-171. [CrossRef] [PubMed]

28. Suhr, K.I.; Nielsen, P.V. Effect of weak acid preservatives on growth of bakery product spoilage fungi at different water activities and $\mathrm{pH}$ values. Int. J. Food Microbiol. 2004, 95, 67-78. [CrossRef] [PubMed]

29. Lavermicocca, P.; Valerio, F.; Evidente, A.; Lazzaroni, S.; Corsetti, A.; Gobbetti, M. Purification and characterization of novel antifungal compounds from the sourdough Lactobacillus plantarum strain 21B. Appl. Environ. Microbiol. 2000, 66, 4084-4090. [CrossRef] [PubMed]

30. Dao, T.; Dantigny, P. Control of food spoilage fungi by ethanol. Food Control 2011, 22, 360-368. [CrossRef]

31. Katsinis, G.; Rigas, F.; Doulia, D. Synergistic effect of chemical preservatives with ethanol on the microbial shelf life of bread by factorial design. Int. J. Food Sci. Technol. 2008, 43, 208-215. [CrossRef]

32. Berni, E.; Scaramuzza, N. Effect of ethanol on growth of Chrysonilia sitophila ('the red bread mould') and Hyphopichia burtonii ('the chalky mould') in sliced bread. Lett. Appl. Microbiol. 2013, 57, 344-349. [CrossRef] [PubMed]

33. Hempel, A.W.; O'Sullivan, M.G.; Papkovsky, D.B.; Kerry, J.P. Use of smart packaging technologies for monitoring and extending the shelf-life quality of modified atmosphere packaged (MAP) bread: Application of intelligent oxygen sensors and active ethanol emitters. Eur. Food Res. Technol. 2013, 237, 117-124. [CrossRef]

34. Corsetti, A.; Gobbetti, M.; De Marco, B.; Balestrieri, F.; Paoletti, F.; Russi, L.; Rossi, J. Combined effect of sourdough lactic acid bacteria and additives on bread firmness and staling. J. Agric. Food Chem. 2000, 48, 3044-3051. [CrossRef] [PubMed]

35. Moroni, A.V.; Dal Bello, F.; Arendt, E.K. Sourdough in gluten-free bread-making: An ancient technology to solve a novel issue? Food Microbiol. 2009, 26, 676-684. [CrossRef] [PubMed]

36. Axel, C.; Brosnan, B.; Zannini, E.; Furey, A.; Coffey, A.; Arendt, E.K. Antifungal sourdough lactic acid bacteria as biopreservation tool in quinoa and rice bread. Int. J. Food Microbiol. 2016, 239, 86-94. [CrossRef] [PubMed]

37. Kirschner, L.M.; Von Holy, A. Rope spoilage of bread. S. Afr. J. Sci. 1989, 85, 425-427.

38. Schnürer, J.; Magnusson, J. Antifungal lactic acid bacteria as biopreservatives. Trends Food Sci. Technol. 2005, 16, 70-78. [CrossRef]

39. Gänzle, M.G. Reutericyclin: Biological activity, mode of action, and potential applications. Appl. Microbiol. Biotechnol. 2004, 64, 326-332. [CrossRef] [PubMed]

40. Ryan, L.A.M.; Dal Bello, F.; Arendt, E.K. The use of sourdough fermented by antifungal LAB to reduce the amount of calcium propionate in bread. Int. J. Food Microbiol. 2008, 125, 274-278. [CrossRef] [PubMed]

41. Gobbetti, M.; De Angelis, M.; Corsetti, A.; Di Cagno, R. Biochemistry and physiology of sourdough lactic acid bacteria. Trends Food Sci. Technol. 2005, 16, 57-69. [CrossRef]

42. Dal Bello, F.; Clarke, C.I.; Ryan, L.A.M.; Ulmer, H.; Schober, T.J.; Ström, K.; Sjögren, J.; van Sinderen, D.; Schnürer, J.; Arendt, E.K. Improvement of the quality and shelf life of wheat bread by fermentation with the antifungal strain Lactobacillus plantarum FST 1.7. J. Cereal Sci. 2007, 45, 309-318. [CrossRef]

43. Coda, R.; Cassone, A.; Rizzello, C.G.; Nionelli, L.; Cardinali, G.; Gobbetti, M. Antifungal activity of Wickerhamomyces anomalus and Lactobacillus plantarum during sourdough fermentation: Identification of novel compounds and long-term effect during storage of wheat bread. Appl. Environ. Microbiol. 2011, 77, 3484-3492. [CrossRef] [PubMed]

44. Coda, R.; Rizzello, C.G.; Nigro, F.; De Angelis, M.; Arnault, P.; Gobbetti, M. Long-Term Fungal Inhibitory Activity of Water-Soluble Extracts of Phaseolus vulgaris cv. Pinto and Sourdough Lactic Acid Bacteria during Bread Storage. Appl. Environ. Microbiol. 2008, 74, 7391-7398. [CrossRef] [PubMed]

45. European Commission. Commission Regulation (EC) No 450/2009 of 29 May 2009 on active and intelligent materials and articles intended to come into contact with food. Off. J. Eur. Union 2009, L 135, 3-11.

46. Ahvenainen, R. Novel Food Packaging Techniques; Woodhead Publishing: Boca Raton, FL, USA, 2003; ISBN 978-1-85573-675-7. 
47. Coles, R.; McDowell, D.; Kirwan, M.J. (Eds.) Food Packaging Technology, 1st ed.; Blackwell: Oxford, UK, 2003; ISBN 978-0-8493-9788-2.

48. Soares, N.F.F.; Rutishauser, D.M.; Melo, N.; Cruz, R.S.; Andrade, N.J. Inhibition of microbial growth in bread through active packaging. Packag. Technol. Sci. 2002, 15, 129-132. [CrossRef]

49. Salminen, A.; Latva-Kala, K.; Randell, K.; Hurme, E.; Linko, P.; Ahvenainen, R. The effect of ethanol and oxygen absorption on the shelf-life of packed sliced rye bread. Packag. Technol. Sci. 1996, 9, 29-42. [CrossRef]

50. Berenzon, S.; Saguy, I.S. Oxygen Absorbers for Extension of Crackers Shelf-life. LWT Food Sci. Technol. 1998, 31, 1-5. [CrossRef]

51. Nielsen, P.V.; Rios, R. Inhibition of fungal growth on bread by volatile components from spices and herbs, and the possible application in active packaging, with special emphasis on mustard essential oil. Int. J. Food Microbiol. 2000, 60, 219-229. [CrossRef]

52. Latou, E.; Mexis, S.F.; Badeka, A.V.; Kontominas, M.G. Shelf life extension of sliced wheat bread using either an ethanol emitter or an ethanol emitter combined with an oxygen absorber as alternatives to chemical preservatives. J. Cereal Sci. 2010, 52, 457-465. [CrossRef]

53. Galić, K.; Curić, D.; Gabrić, D. Shelf life of packaged bakery goods-A review. Crit. Rev. Food Sci. Nutr. 2009, 49, 405-426. [CrossRef] [PubMed]

54. European Commission. Commission Regulation (EU) No 10/2011 of 14 January 2011 on plastic materials and articles intended to come into contact with food Text with EEA relevance. Off. J. Eur. Union 2011, L 12, $1-89$.

55. Labuza, T.P.; Breene, W.M. Applications of "active Packaging" for Improvement of Shelf-Life and Nutritional Quality of Fresh and Extended Shelf-Life Foods. J. Food Process. Preserv. 1989, 13, 1-69. [CrossRef]

56. Franke, I.; Wijma, E.; Bouma, K. Shelf life extension of pre-baked buns by an ACTIVE PACKAGING ethanol emitter. Food Addit. Contam. 2002, 19, 314-322. [CrossRef] [PubMed]

57. Smith, J.P.; Ramaswamy, H.S.; Simpson, B.K. Developments in food packaging technology. Part II. Storage aspects. Trends Food Sci. Technol. 1990, 1, 111-118. [CrossRef]

58. Koukoutsis, J.; Smith, J.P.; Daifas, D.P.; Yayalan, V.; Cayouette, B.; Ngadi, M.; El-Khoury, W. In vitro studies to control the growth of microorganisms of spoilage and safety concern in high-moisture, high-pH bakery products. J. Food Saf. 2004, 24, 211-230. [CrossRef]

59. De Azeredo, H.M.C. Nanocomposites for food packaging applications. Food Res. Int. 2009, 42, $1240-1253$. [CrossRef]

60. Mihindukulasuriya, S.D.F.; Lim, L.-T. Nanotechnology development in food packaging: A review. Trends Food Sci. Technol. 2014, 40, 149-167. [CrossRef]

61. Sekhon, B.S. Food nanotechnology-An overview. Nanotechnol. Sci. Appl. 2010, 3, 1-15. [PubMed]

62. Sondi, I.; Salopek-Sondi, B. Silver nanoparticles as antimicrobial agent: A case study on E. coli as a model for Gram-negative bacteria. J. Colloid Interface Sci. 2004, 275, 177-182. [CrossRef] [PubMed]

63. Hu, A.W.; Fu, Z.H. Nanotechnology and its application in packaging and packaging machinery. Packag. Eng. 2003, 24, 22-24.

64. Sharma, P.; Oey, I.; Bremer, P.; Everett, D.W. Microbiological and enzymatic activity of bovine whole milk treated by pulsed electric fields. Int. J. Dairy Technol. 2017. [CrossRef]

65. Azeredo, H. Antimicrobial Activity of Nanomaterials for Food Packaging Applications. In Nano-Antimicrobials; Cioffi, N., Rai, M., Eds.; Springer: Berlin, Germany, 2012; pp. 375-394, ISBN 978-3-642-24427-8.

66. Völker, C.; Oetken, M.; Oehlmann, J. The biological effects and possible modes of action of nanosilver. Rev. Environ. Contam. Toxicol. 2013, 223, 81-106. [CrossRef] [PubMed]

67. Pietrzak, K.; Glińska, S.; Gapińska, M.; Ruman, T.; Nowak, A.; Aydin, E.; Gutarowska, B. Silver nanoparticles: A mechanism of action on moulds. Metallomics 2016, 8, 1294-1302. [CrossRef] [PubMed]

68. Prabhu, S.; Poulose, E.K. Silver nanoparticles: Mechanism of antimicrobial action, synthesis, medical applications, and toxicity effects. Int. Nano Lett. 2012, 2, 32. [CrossRef]

69. Feng, Q.L.; Wu, J.; Chen, G.Q.; Cui, F.Z.; Kim, T.N.; Kim, J.O. A mechanistic study of the antibacterial effect of silver ions on Escherichia coli and Staphylococcus aureus. J. Biomed. Mater. Res. 2000, 52, 662-668. [CrossRef]

70. Limbach, L.K.; Wick, P.; Manser, P.; Grass, R.N.; Bruinink, A.; Stark, W.J. Exposure of engineered nanoparticles to human lung epithelial cells: Influence of chemical composition and catalytic activity on oxidative stress. Environ. Sci. Technol. 2007, 41, 4158-4163. [CrossRef] [PubMed] 
71. Orsuwan, A.; Shankar, S.; Wang, L.; Sothornvit, R.; Rhim, J. Preparation of antimicrobial agar/banana powder blend films reinforced with silver nanoparticles. Food Hydrocoll. 2016, 60, 476-485. [CrossRef]

72. Kanmani, P.; Rhim, J.-W. Physicochemical properties of gelatin/silver nanoparticle antimicrobial composite films. Food Chem. 2014, 148, 162-169. [CrossRef] [PubMed]

73. De Faria, A.F.; Martinez, D.S.T.; Meira, S.M.M.; de Moraes, A.C.M.; Brandelli, A.; Filho, A.G.S.; Alves, O.L. Anti-adhesion and antibacterial activity of silver nanoparticles supported on graphene oxide sheets. Colloids Surf. B Biointerfaces 2014, 113, 115-124. [CrossRef] [PubMed]

74. Taglietti, A.; Arciola, C.R.; D’Agostino, A.; Dacarro, G.; Montanaro, L.; Campoccia, D.; Cucca, L.; Vercellino, M.; Poggi, A.; Pallavicini, P.; et al. Antibiofilm activity of a monolayer of silver nanoparticles anchored to an amino-silanized glass surface. Biomaterials 2014, 35, 1779-1788. [CrossRef] [PubMed]

75. Sharma, C.; Dhiman, R.; Rokana, N.; Panwar, H. Nanotechnology: An Untapped Resource for Food Packaging. Front. Microbiol. 2017, 8. [CrossRef] [PubMed]

76. Ludueña, L.N.; Alvarez, V.A.; Vazquez, A. Processing and microstructure of PCL/clay nanocomposites. Mater. Sci. Eng. A 2007, 460-461, 121-129. [CrossRef]

77. Agarwal, A.; Raheja, A.; Natarajan, T.; Chandra, T.S. Effect of electrospun montmorillonite-Nylon 6 nanofibrous membrane coated packaging on potato chips and bread. Innov. Food Sci. Emerg. Technol. 2014. [CrossRef]

78. Mihaly Cozmuta, A.; Peter, A.; Mihaly Cozmuta, L.; Nicula, C.; Crisan, L.; Baia, L.; Turila, A. Active Packaging System Based on $\mathrm{Ag} / \mathrm{TiO}_{2}$ Nanocomposite Used for Extending the Shelf Life of Bread. Chemical and Microbiological Investigations. Packag. Technol. Sci. 2015, 28, 271-284. [CrossRef]

79. Peter, A.; Mihaly-Cozmuta, L.; Mihaly-Cozmuta, A.; Nicula, C.; Ziemkowska, W.; Basiak, D.; Danciu, V.; Vulpoi, A.; Baia, L.; Falup, A.; et al. Changes in the microbiological and chemical characteristics of white bread during storage in paper packages modified with $\mathrm{Ag} / \mathrm{TiO}_{2}-\mathrm{SiO}_{2}, \mathrm{Ag} / \mathrm{N}-\mathrm{TiO}_{2}$ or $\mathrm{Au} / \mathrm{TiO}_{2}$. Food Chem. 2016, 197, 790-798. [CrossRef] [PubMed]

80. Bumbudsanpharoke, N.; Ko, S. Nano-food packaging: An overview of market, migration research, and safety regulations. J. Food Sci. 2015, 80, R910-923. [CrossRef] [PubMed]

81. Blanco-Padilla, A.; Soto, K.M.; Hernández Iturriaga, M.; Mendoza, S. Food Antimicrobials Nanocarriers. Available online: https:/ / www.hindawi.com/journals/tswj/2014/837215/ (accessed on 27 December 2017).

82. Barbosa-Canovas, G.V.; Mortimer, A.; Lineback, D.; Spiess, W.; Buckle, K.; Colonna, P. Global Issues in Food Science and Technology; Academic Press: San Diego, CA, USA, 2009; ISBN 978-0-08-092081-8.

83. Otoni, C.G.; Pontes, S.F.O.; Medeiros, E.A.A.; de Fátima Ferreira Soares, N. Edible films from methylcellulose and nanoemulsions of clove bud (Syzygium aromaticum) and oregano (Origanum vulgare) essential oils as shelf life extenders for sliced bread. J. Agric. Food Chem. 2014, 62, 5214-5219. [CrossRef] [PubMed]

84. Gutiérrez, L.; Batlle, R.; Andújar, S.; Sánchez, C.; Nerín, C. Evaluation of Antimicrobial Active Packaging to Increase Shelf Life of Gluten-Free Sliced Bread. Packag. Technol. Sci. 2011, 24, 485-494. [CrossRef]

85. Souza, A.C.; Goto, G.E.O.; Mainardi, J.A.; Coelho, A.C.V.; Tadini, C.C. Cassava starch composite films incorporated with cinnamon essential oil: Antimicrobial activity, microstructure, mechanical and barrier properties. LWT Food Sci. Technol. 2013, 54, 346-352. [CrossRef]

86. European Parliament and the Council. Regulation (EC) No 1935/2004 of the European Parliament and of the Council of 27 October 2004 on materials and articles intended to come into contact with food and repealing Directives 80/590/EEC and 89/109/EEC. Off. J. Eur. Union 2004, L 338, 4-17.004.

87. Linsinger, T.P.J.; Chaudhry, Q.; Dehalu, V.; Delahaut, P.; Dudkiewicz, A.; Grombe, R.; von der Kammer, F.; Larsen, E.H.; Legros, S.; Loeschner, K.; et al. Validation of methods for the detection and quantification of engineered nanoparticles in food. Food Chem. 2013, 138, 1959-1966. [CrossRef] [PubMed]

(C) 2018 by the authors. Licensee MDPI, Basel, Switzerland. This article is an open access article distributed under the terms and conditions of the Creative Commons Attribution (CC BY) license (http:/ / creativecommons.org/licenses/by/4.0/). 